\title{
Challenges and obstacles in sharing and coordinating information during multi-agency disaster response: Propositions from field exercises
}

\author{
Nitesh Bharosa $\cdot$ JinKyu Lee $\cdot$ Marijn Janssen
}

Published online: 9 May 2009

(C) The Author(s) 2009. This article is published with open access at Springerlink.com

\begin{abstract}
Although various scholars have researched issues regarding disaster management, few have studied the sharing and coordinating of information during disasters. Not much empirical data is available in this field and there is sparse insight into the factors that may impede or facilitate information sharing and coordination among stakeholders. In this paper, we provide an overview of the relevant obstacles and challenges by examining existing literature and then investigating a series of multi-agency disaster management exercises, using observations and a survey. Although all the people who took part in our study agree that sharing information is important, for the success of their own organization as well as the exercise as a whole, the extent to which information is actually being shared among organizations is often limited by a number of factors that can be attributed to the community, agency and individual level. We found that relief workers are often more concerned with receiving information from others than with providing information to others who may benefit. Incentives for sharing information, understanding each other's work-processes and the usability of information
\end{abstract}

The research of the second author has been supported by NSF under grant \# IIS-0809186. The usual disclaimer applies.

\footnotetext{
N. Bharosa $(\bowtie) \cdot$ M. Janssen

Delft University of Technology,

Jaffalaan 5, 2628BX Delft, The Netherlands

e-mail: n.bharosa@tudelft.nl

M. Janssen

e-mail: m.f.w.h.a.janssen@tudelft.nl

J. Lee

Spears School of Business,

Oklahoma State University,

380 North Hall, 700 N. Greenwood Ave.,

Tulsa, OK 74106, USA

e-mail: Jinkyu_lee@hotmail.com
}

systems have shown positive effects on information sharing and coordination. The findings of our study have been formulated using six grounded propositions, which can be used by system designers and policy-makers upon validation in further research. We also provide directions for future research.

Keywords Coordination · Information sharing · Crisis . Field exercise $\cdot$ System design

\section{Introduction}

In 2005, an advisory committee to the Dutch Ministry of Internal Affairs and Kingdom Relations concluded that enabling shared access to information among autonomous relief agencies is the main bottleneck when it comes to effective inter-agency crisis response in the Netherlands (ACIR 2005). In 2008, the national workshop "All Hands on Deck", in which top Dutch government officials and relief agency commanders participated (ASE 2008), concluded that the challenges that were identified in the past continue to be relevant today. Recent studies in the US (e.g., Chen et al. 2008b) have drawn similar conclusions. Information sharing and coordination remains at the top of the research agenda, despite all progress that may have been made over the years.

So why is it so difficult for autonomous relief agencies to share and coordinate information? Various scholars (e.g., Auf der Heide 1989; Kapucu 2006) suggest that it probably has to do with the unpredictable, dynamic and complex nature of the environment in which multiple groups of professionals need to collaborate. Nevertheless, improvements in these areas is crucially important because access to core information enhances the efficiency and effectiveness 
of responses as well as coordination throughout the network of responding organizations (Comfort et al. 2004b; Horan and Schooley 2007). There are a number of studies that provide evidence suggesting that poor information sharing and coordination during inter-agency disaster response has a negative influence on collective decision-making and actions (e.g., Dawes et al. 2004; Helsloot 2005; Junglas and Ives 2007; Pan et al. 2005). The need for coordination in disaster management is undisputed, with lack of coordination leading to a number of possible failures, for instance inappropriate allocations of first responder resources, counter-productive ordering of sequential relief processes, and delayed evacuations, which often result in crisis escalation and even higher numbers of causalities.

Despite its obvious significance, coordination in the area of disaster response has thus far received relatively little scientific attention (Chen et al. 2008a). Little is known about the challenges and obstacles when it comes to sharing and coordinating information effectively (Ren et al. 2008). This lack of understanding can be attributed to sparse empirical studies in this area. While previous studies often involve a post - disaster evaluation, few have examined what is happening during a disaster. Also, the topic has usually been investigated from a single stakeholder's perspective (Ren et al. 2008). Accordingly, the main objective of this study is to produce an objective and systematic overview of the obstacles and challenges in effective disaster information sharing and coordination by observing and surveying disaster response exercises.

In the next section, we present a literature review on coordination and information sharing problems, identifying a set of obstacles and challenges at the community, agency and individual levels. Next, the research method, consisting of exercise observations and a survey, is described in details. Then a summary of observed emergency response exercises and the findings from our qualitative analysis are presented, followed by the results of our survey study. Combining the findings from the qualitative and quantitative studies, we then present six grounded propositions. We conclude by discussing our findings and providing recommendations for policymakers, practitioners and researchers.

\section{Obstacles and challenges found in literature}

\subsection{Coordination levels}

Coordination takes place at various levels of crisis management (Comfort et al. 2004a). A widely accepted definition of coordination is the one suggested by Malone and Crowston (1990), who define the concept as "managing dependences between entities" and argue that the need for coordination arises from constraints imposed on the performance of tasks by the interdependent nature of these tasks. Multi-agency coordination typically deals with the coordination of various organizations, each with their own processes, information, applications and other technology. Bots and Sol (1988) provide three perspectives to coordination: the micro-perspective, focusing on coordination among individuals, the intermediate perspective, focusing on organizations, and the macro-perspective, which adopts an inter-organizational approach. We prefer the term community over inter-organizational, because it refers not only to a legal entity, but also to the entire community involved. We use the term agency instead of organization to avoid confusion surrounding the organizational elements at the community level (e.g., inter-agency relationships). Using this perspective, we analyze coordination from a community (macro), agency (intermediate) and individual (micro) level.

At the community level, disaster management involves a complex network of interdependent agencies (Bigley and Roberts 2001), which involves numerous, often unprecedented, interactions within and between various relief agencies. We need to keep in mind that, in non-disaster situations, many of the agencies involved operate independently of each other. In a disaster situation, complexity arises from a variety of elements, systems, processes and actors, and it is hard to get a clear picture of the entire situation within the timeframe of a crisis (McEntire 2002). In this context, complexity not only refers to the number of actors in the network, but also to the many interactions between them at the various organizational levels (Rao et al. 1995). Such interactions are necessary for achieving mutual adjustment and collective mindfulness (Weick and Sutcliffe 2001). At the community level, information needs to flow in a coordinated fashion through a multiorganizational and multi-level grid, which means that the functioning of the organizations involved not only depends on their internal interactions, but on the interactions with other agencies as well. There may be no central coordinating authority across all level (Denning 2006). Instead, the agencies involved are coordinated by several, pre-agreed agency leaders at various response levels. Many interorganizational dependencies may not always be clearly visible. These dependencies and the resulting interactions are of crucial importance, as demonstrated by the disorganized multi-agency response to the $9 / 11$ attacks, where police and fire departments were unable to share information (Kean and Hamilton 2004).

When looking at the agency level, it becomes clear that responding to an extreme event requires collaboration and transparency on the part of various agencies with different cultures and organizational structures (Mendonça et al. 2007). Even though many scholars (e.g., Auf der Heide 
1989; Comfort and Kapucu 2006) view the organizational structures of relief agencies as military style, hierarchical, command and control structures, they are in fact not completely similar because the various relief agencies face different kinds of challenges under normal circumstances. Some relief agencies are highly disciplined, others disorderly; some have a highly hierarchical structure, while others are more informal and egalitarian. In some cases, authoritarian decision-making prevails, while others tend to adopt a more democratic approach (Granot 1997). Every relief agency focuses on a different set of challenges in its daily operations and has developed distinct and tailored roles, procedures and capabilities designed to address these challenges. Under normal circumstances, the organizational structures of the separate agencies pose no major problems. However, when disaster strikes, coordination becomes much more difficult, simply because a disaster is more than merely a big emergency (Quarantelli 1982).

At the individual level, there are other kinds of obstacles. Deciding and acting in an disaster response situation is a challenging process for each individual, because everyone is faced with severe time-pressure and a flood of information that may be inaccurate or out-dated by the time a decision or action takes place. Such a complex, intense and information-rich environment can easily result in cognitive overload at an individual level (de Greef and Arciszewski 2007), because a decision-maker's mental capacity (due to the time to concentrate and the sheer number of available alternatives to consider) is limited (Lindblom 1968; March 1988). This cognitive overload is related to a human limitation that is known as 'bounded rationality' (Simon 1982) and that constitutes a well-known bottleneck in human information processing. Cognition is related to role performance or, in other words, the execution of a set of behaviors that an individual is expected to be able to perform (Mendonca et al. 2007). This negative relationship between information requirements and cognitive capacity (Galbraith 1977) exists at the individual level, resulting in a performance level that may not correlate with the amount of information available (Rao et al. 1995). As such, it is important to determine how much information people need and can be exposed to at an individual level with regard to disaster management.

\subsection{Information sharing and coordination problems}

Contingency theory (Galbraith 1973; Van de Ven and Drazin 1985) and institutional theory (Berger and Luckman 1967; Stinchcombe 1997) are alternative, though not mutually exclusive, theories that try to explain how disaster management organizations (DMOs) change their operational processes and structures in response to significant changes in the environment. Institutional theory attends to the deeper and more resilient aspects of social structure by looking at the processes by which structures are established. Often, a distinction is drawn between organizations and institutions, by which organizations are presupposed to reward effectiveness, efficiency and control over production, while institutional environments reward normative requirements of appropriateness and legitimacy and, in some cases, conformity to procedures, presentations, symbols and rhetoric (e.g., Fountain 2001). In this study, we use both theories, which emphasize institutional rules (e.g., routine operational procedures) and relative power among social actors to explain the way organizations respond to changes in the intra/inter/extra-organizational environment, rather than relying solely on market mechanisms and economic rationality (albeit it be bounded) of decision-makers (Fligstein and Dauber 1989).

In both intra and inter-agency interactions, information is considered a primary asset that needs to be produced, retrieved, processed, enriched, validated, consumed and/or distributed within the inter-agency network. Information technology (IT) and the information attributes it produces thus represent a crucial dimension of the sharing and coordination of information. Because the environment during a disaster is dynamic (Comfort et al. 2001), information may well be outdated by the time it is collected (e.g., Fisher and Kingma 2001). For instance, in case of a major disaster, the state and configuration of human and other types of resources keep on changing. Moreover, the impact of the event, for instance the death toll of a fire, earthquake or storm, may not be static. The high level of uncertainty (Argote 1982) and unpredictability with regard to the required information (Longstaff 2005) emphasize the crucial role of IT. As the disaster unfolds, dealing with uncertainty often requires action which simultaneously generates the raw information that is used for sensemaking and affects the unfolding disaster itself (Weick 1988).

Information technology is essential to improving information-sharing and decision-making for emergency responders (Graves 2004), as it has already drastically reshaped the way organizations interact with each other (Lee and Whang 2000). Technological aspects of InterOrganizational Information-Sharing Systems (IOISS) can enable or impede the coordination and sharing of disasterrelated information. High levels of integration and use of technology are likely to result in high levels of information sharing. On the other hand, forwarding all the available information to every individual involved in the disaster response effort will result in a serious information overload. IT can be used to make sure that everyone receives the relevant information at the right time.

A number of studies have found evidence of poor information sharing and coordination in inter-agency disaster response situations (e.g., Dawes et al. 2004; 
Table 1 Overview of information sharing and coordination problems

\begin{tabular}{|c|c|c|c|}
\hline Coordination level & Perspective being adopted & Typical problems & Sources \\
\hline 1. Community & $\begin{array}{l}\text { Institutionalization and political } \\
\text { power between actors, } \\
\text { Inter-organizational } \\
\text { interdependencies and } \\
\text { collaboration procedures. }\end{array}$ & $\begin{array}{l}\text { Organizational silos, no } \\
\text { incentives for horizontal } \\
\text { information sharing, conflicting } \\
\text { role structures, mismatch } \\
\text { between goals, independent } \\
\text { projects, ack of meetings, } \\
\text { standardization / interoperability, } \\
\text { heterogeneous systems. }\end{array}$ & $\begin{array}{l}\text { (Bui et al. 2000; Dawes et al. } \\
\text { 2004; De Bruijn 2006; Kouzmin } \\
\text { et al. 1995; Miller et al. 2005; } \\
\text { Weick 1993) }\end{array}$ \\
\hline 2. Agency & $\begin{array}{l}\text { Organizational procedures, } \\
\text { division of roles, tasks } \\
\text { and responsibilities, } \\
\text { standards, values and rules. }\end{array}$ & $\begin{array}{l}\text { Reliance on protocols, focus } \\
\text { on vertical information sharing, } \\
\text { allocation of responsibilities, } \\
\text { contact persons, privacy, security } \\
\text { and authentication. }\end{array}$ & $\begin{array}{l}\text { (Comfort and Kapucu 2006; } \\
\text { Drabek and McEntire 2002; } \\
\text { Dynes and Aguirre 1976; } \\
\text { Faraj and Xiao 2006; } \\
\text { Otjacques et al. 2007) }\end{array}$ \\
\hline 3. Individual & $\begin{array}{l}\text { Human cognition/perception } \\
\text { of uncertainty and time pressure, } \\
\text { Personal propensity to adopt innovations } \\
\text { Task environments and task execution, }\end{array}$ & $\begin{array}{l}\text { Information overload, inability to } \\
\text { determine what should be shared, } \\
\text { misinterpretation of information, } \\
\text { bounded rationality, prioritization } \\
\text { of own problems, information } \\
\text { quality, system quality, access limit }\end{array}$ & $\begin{array}{l}\text { (Argote 1982; Chen and } \\
\text { Dahanayake 2006; } \\
\text { 2007; Lin and Su 1998) } \\
\text { (Fisher and Kingma 2001; } \\
\text { Helbing et al. 2006; } \\
\text { Helsloot 2005) }\end{array}$ \\
\hline
\end{tabular}

Helsloot 2005; Junglas and Ives 2007; Pan et al. 2005), which can be assigned to the community, agency or individual level. The effectiveness of information sharing and coordination will be determined by the combination of the problems that have been identified at the three levels. Table 1 contains the obstacles and challenges that can occur during multi-agency disaster management as identified in existing literature.

Keeping in mind the three levels of coordination indicated in Table 1, our aim is to identify institutional as well as technological factors that may impede information sharing and coordination. To do so, we have adopted the following research approach.

\section{Research approach}

Although a number of studies have examined this area, empirical analysis of information sharing and coordination obstacles during multi-agency disaster response is relatively scarce. One practical reason for this state of affairs may be that it is relatively difficult to collect empirical data during a real disaster, because the situation involved is unforeseeable and dangerous and may make it impossible to come near the disaster site. Moreover, in disaster research, various problems with regard to context, event, scope, control and time make it difficult to collect data from the field (Killian 2002). To collect data on disaster management and information sharing, we decided to conduct a case study on multi-agency disaster management (hereafter referred to as MDM) exercises in the Port of Rotterdam (POR), the Netherlands. The exercises were conducted on June 5th, 19th and 26th of 2007. Each day two exercises took place, and each exercise lasted for about $3 \mathrm{~h}$. In all, we observed six exercises, each of which involved about 30 participants. The participants in the exercises were unaware of what was going to unfold. Neither the situations nor the participants were controlled or manipulated by the researchers. Although a real disaster may unfold differently from the events that were portrayed in the various exercises, the relief workers were committed to achieving the objectives of the exercises and they took what happened very seriously. The primary research instruments that we used were (a) participatory observation and (b) questionnaire surveys. We take a more detailed look at both these research instruments in the following sub-sections.

Observing relief workers in action provides researchers with a very rich understanding of emergency response operations. It allowed us to collect information on all the coordination levels (community, agency and individual levels) of the object under investigation. Moreover, observation sometimes allows researchers to interview relief workers on the spot, for instance to better understand their actions or to ask them to specify the problems they are facing. The exercises were observed by a team of three observers, each positioned at a different location in the exercise area; one at each of the two decision-making units near the scene and a third one in the remote emergency control room. The exercises were observed and recorded based on a predefined observation protocol. The observation protocol contained questions regarding the actors, coordination model, information flows and information systems that were used. During the exercises, we observed the information exchange between the organizations, 
processes, problems and technologies, using systematic schemes such as event logs and matrixes.

Based on the first round of observations, we designed and conducted a questionnaire survey ${ }^{1}$ to augment and triangulate our observation findings. We designed paperbased questionnaire that was distributed to the participants at the end of 2 days. Participation in the survey was voluntary and anonymous. Of the 180 participants, 75 (or a $42 \%$ response rate) provided usable responses. The survey contained no questions that could be used to identify participants and the individual questionnaires were not passed on to any of the authorities. The response rate was higher than that usually found in typical MIS survey studies. In recent years, survey studies published in MIS journals (e.g., JMIS) have reported response rates of $30 \%$ or less from surveys conducted among a group of organizational IT users (e.g., IT managers/employees). We feel that our personal presence during the exercises played a role in ensuring the relatively high response rate. The responders also indicated they were interested in finding out how our results could help improve their performance. Most non-respondents were people who left the site to resume their regular duty before we were able to hand them the survey. We observed no sign of systematic bias in the survey respondent group. The respondent represented national (24\%), provincial (16\%), and local (44\%) level government organizations, as well as several private sector emergency management organizations $(8 \%)$ and NGOs $(8 \%)$. In terms of the functional areas, emergency response communities (i.e., police, fire departments, emergency medical services) represented a majority $(68.9 \%)$, followed by Anti/Counter-Terrorism (ACT) and intelligence communities (19\%). The other areas included private-sector critical infrastructure protection agencies and research communities. In this paper, we focus on the results of our exploratory statistical analyses that support or contradict our understandings, and on the predictions that emerged from the case study results.

The setting of the exercises imposed some restrictions on data collection. We were not allowed to video-tape the exercises, nor were we able to log communication, and because the participants were expected to resume their daily duties as soon as they completed the exercise, the amount of time available to us to distribute the survey proved limited. For reasons of privacy, we were unable to send the surveys by mail or e-mail to the participants we missed. Finally, to ensure that our presence did not interfere with the exercises, we were not allowed to get too close to the relief activities.

\footnotetext{
${ }^{1}$ Questionnaire items will be available from the corresponding author upon request.
}

\section{Crisis response case study and exercises}

\subsection{Case background}

With about 10,500 ha, the Port of Rotterdam (PoR) (www. portofrotterdam.nl) is one of the world's largest seaports. An estimated 1,600 companies operate in this major harbor area. Every day, enormous quantities of chemicals and other hazardous materials are imported, transferred and stored. Storing and transferring these dangerous materials is potentially catastrophic for life and infrastructure in the area. Obviously, when a disaster unfolds in such a large and hazard-prone area, responding adequately requires efficient and effective disaster management. ${ }^{2}$ To make sure that all the affected organizations are up to the task, the Safety Region Rotterdam-Rijnmond stimulates regular disaster management exercises in the Port. The exercises usually take place on a large scale because they involve all the primary relief agencies in the Port region.

The objective of the disaster management exercises was to train the public relief agencies for multi-agency disaster response. In daily operations, the police, fire brigade and ambulance services work autonomously. They respond together only in cases where they cannot handle incidents on their own, which is a situation that does not occur frequently. In the case of the Rotterdam Harbor area, the same applies to the Rotterdam Port Authority. To prepare the various services in the area to decide and act collectively during a disaster, the MDM exercises are organized on a regular basis. The focus in the exercises we attended was on joint decision-making at a tactical response level in which police departments, fire departments, ambulance services, the Port Authority, chemical experts, and the army had to share a central control room and coordinate information.

The scenario for the first and second exercise day involved a major gas leak at the Unilever Factory in Vlaardingen. Because this facility is located near a residential area, the gas leak posed a major health hazard to nearby residents. The scenario for the third exercise day involved a number of explosions on a major cruise ship in the harbor area. Moreover, the Dutch royal family was on the cruise ship and needed to be evacuated at once. This made the third day scenario slightly more difficult. The elements and time sequence of the scenario were described

\footnotetext{
${ }^{2}$ Note that we draw a distinction between incidents and disaster. We define everyday, predictable events that people have trained for as incidents (e.g., small fire, robbery, traffic accidents). Once an incident exceeds a certain magnitude, has a broad exposure, exhibits unpredicted events, and cannot be considered a routine accident that can be solved independently by one or several different service organizations, we talk about a disaster.
} 
Fig. 1 Observed command structure during inter-agency response

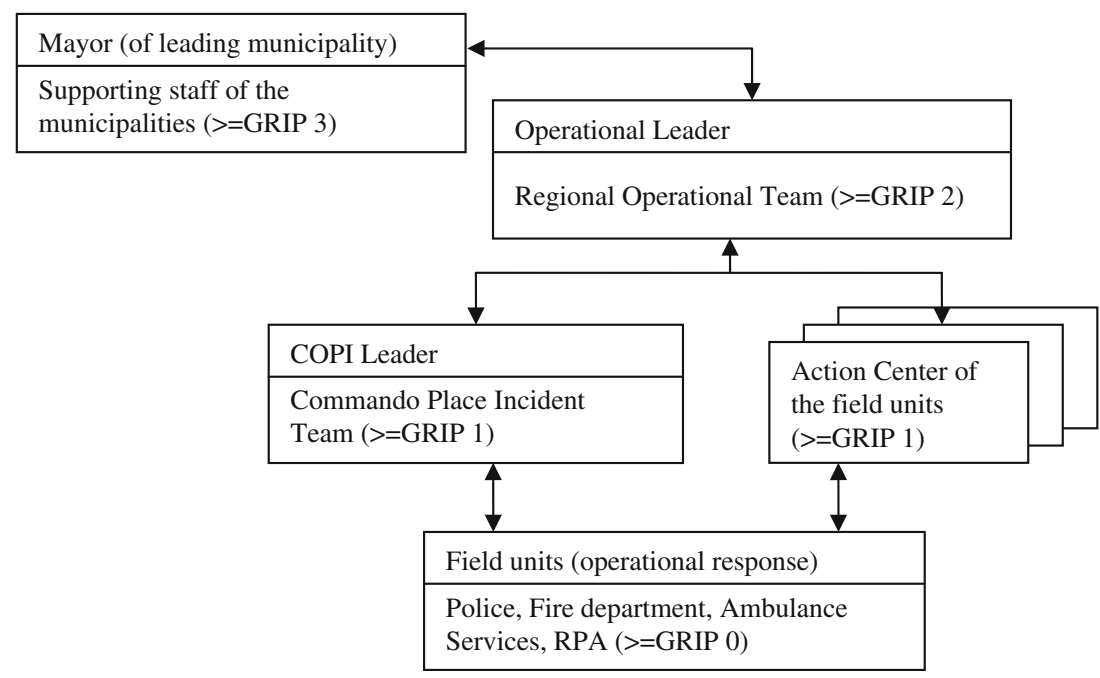

in a script. The exercise leaders used the script to coordinate the exercise.

\subsection{Analysis of the coordination levels}

Analysis of the information sharing and coordination at the community, agency and individual level reveals a complex structure with lots of interdependencies. Multi-agency disaster response requires the joint operation of various relief agencies. Which agencies would participate in the exercises was determined according to the Coordinated Response Plan (abbreviated as GRIP in Dutch) proposed by the government. In practical terms this means that, for each exercise, the local police department, fire brigade, ambulance services, Rotterdam Port Authority (RPA), the three municipalities in the Harbor Area, and chemical experts were involved. In addition, due to recently passed legislation on disaster management, the national army is also required to act as relief agency during major response efforts. During these exercises, one representative of the national army participated in the form of a pilot.

The commanding officers of the relief agencies meet on two levels of decision-making: the Regional Operational Team (ROT) and the Commando ${ }^{3}$ Place Incident team (COPI). While the ROT is usually organized on a predetermined location, the COPI is set up in a container truck close to the incident area and near the field units. Both decision-making units consist of a regular staff, support staff and ad-hoc/situation-dependent advisors (e.g., experts from companies in the area, public infrastructure managers). Figure 1 illustrates the observed coordination structure which was later enriched by documentation provided by the Safety Region Rotterdam-Rijnmond (Staf-

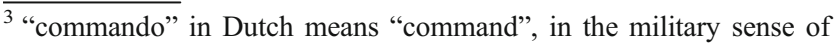
the word.
}

directie Risico- en Crisisbeheersing 2006). For GRIP 3 situations, the Mayor of the municipality in which the source of the disaster is located has final responsibility.

The Mayor is informed by the leader of the ROT, who in turn is informed by the COPI leader. All the leaders are informed and supported by the commanding officers of the relief agencies. The regular relief agencies involved were the police departments, the fire departments, the Port Authority, municipality officials and the ambulance services in the region. The support staff consisted of lower ranking officials with disaster management-related tasks such as information management, press management and control room communication. The action centers of the field units are usually housed in physical containers near the disaster site, similar to the ones used by COPI. These action centers are also known as the 'low control' of the three major relief agencies (police, fire department and ambulance services) and serve as control rooms for the respective agency commanders after each COPI meeting. It was only for this type of exercise that chemical consultancies, company staff, infrastructure managers and representatives of shipping/cargo companies in the region were involved.

One institution not included in Fig. 1 is the supporting Emergency Response Center (ERC), an organization similar to the Public Safety Answering Point in the US (a.k.a. 9-1-1 emergency dispatch center), because this center is not part of the command control structure and has only a facilitating role. Unlike its American counterpart, each ERC acts as an information center for just one of the relief agencies.

\subsection{Information sharing}

During the exercises, we identified various information flows, both across multiple levels and between multiple 
agencies. The information flows were ad-hoc and also depended on the type of information (e.g., static information, such as location maps vs. dynamic information, such as casualty count). Although some of the information flows were formal (according to the command structure), some were informal and involved personal calls using mobile phones between relief agents. Multi-level information flows took place across the operational, tactical and strategic levels of individual agencies. Most of the multi-level information flows were mediated by the ERCs.

The ERC in the Rotterdam region is unique in the Netherlands in that it was one of the first to combine the control stations of the police department, fire brigade, ambulance services and harbor police (RPA) in the same physical location in the World Port Center. In spite of this, there is still no formal arrangement with regard to the coordination of cross-agency information flows in the control room. As a result, we found that little information was actually shared between the co-located ERCs even though the control room facilities and infrastructure were being shared. Managing some of the information flows between the decision-making units (COPI, ROT) and the ERC is the job of the Information Manager (IM), usually a police officer due to the capacity of this agency, and he is responsible for providing specific information services to decision-making units. In the current situation, the IM is only equipped with a laptop with CityGIS, a geographical information system described in the next section, which limits their services to offered. Figure 2 gives an impression of the formal information flows.

Responses to GRIP level $>=1$ disaster were part of the exercises and consist of two onsite response coordinating entities, one remote decision-making entity and a remote management entity such as an emergency response center (ERC) (see Fig. 2). Onsite response is usually reactive, and the time-frame for coordination is limited (minutes) in comparison to the remote decision-making units (hours).

\subsection{Inter-organizational information sharing systems}

Alongside the agency-specific information systems, four IOISS were dedicated to share information between the autonomous agencies during the exercise. The first system used, CityGIS, was new to all participants and was introduced using a demo prior to the exercise. CityGIS is a Google maps-based geographic information system that is supposed to provide the same location information to all agencies. The second information system was Multiteam, a system that some of the relief workers had worked with in the past. In essence, it is an extended mailing system that

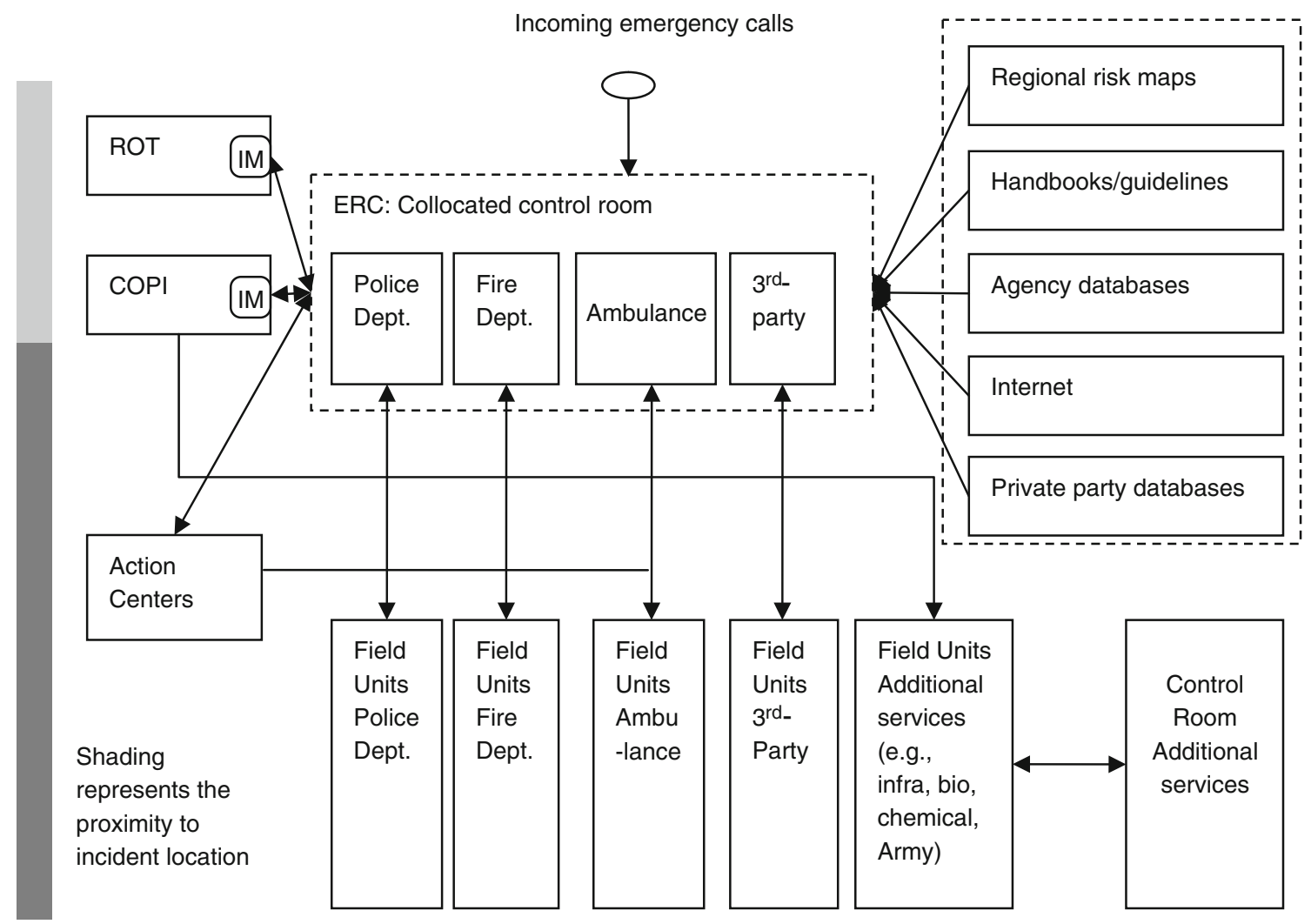

Fig. 2 Information flows observed 
allows relief workers to e-mail situation reports across agencies. The third information system, C2000, is the standard communication system used by almost all relief agencies in the Netherlands and the one the participants in the exercise are likely to use in their everyday operations. In the ERCs, the operators used an additional application called GMS, a Joint Control Room System. The characteristics of the systems are summarized in Table 2.

\subsection{Findings from case study}

In the description of the case study, it becomes clear that there are various factors that exert an influence at the community, agency and individual levels, eventually determining the effectiveness with which information is shared and coordinated between the various agencies involved.

\subsubsection{Community level factors}

The research team was able to observe the institutionalization process of the Coordinated Response Plan (GRIP) during the exercises. Emergency responders from various DMOs worked together according to the plan, demonstrating their awareness of and compliance to the plan. The plan specifies formal inter-agency communication channels (see Fig. 2), as well as the leadership (e.g., COPI, ROT) and the overarching structure of the participating agencies, and the scale of the emergency (GRIP level). The institutionalization of such structures and procedures took place on top of legal and political support. The institutionalized structure and procedures for MDM also allowed for the development of IOISS (i.e., CITIGIS, Multiteam, C2000 and GMS), which can facilitate inter-agency communications during emergency operations. Nevertheless, the actual level of IOISS usage and their effects on the performance at the community level could not be measured because there was no mechanism to do so. This is particularly problematic in the MDM context, where few IOISS functions are used in routine, single-agency operations. While the research team and other external consultants are developing such measures, consensus has yet to be reached as to the value of inter-agency information exchange and mechanisms to encourage the use of IOISS. MDM exercises like the ones we studied provide an invaluable opportunity to evaluate IOISS as well as the design of standard MDM structure and procedures.

The institutionalization of standard structure and procedures can impose limitations on the information flow as well. As shown in Fig. 2, ERC functions as a central hub for all information flows. However, that central hub is, unfortunately, a single point of failure and possesses limited knowledge about ongoing emergency response activities, resulting in uncontrolled information filtering/dissemination and lack of direct information exchange between some information users and information sources. As such, an appropriate interpretation and filtering of information is critical at this level and the ERC needs to find a balance, since neither forwarding all information nor filtering all information is acceptable alternative.

\subsubsection{Agency level factors}

The institutional factors that play a role at the community level can influence every agency in a community because they become the environment for individual agencies operating within the community. However, there may be additional problems that are innate to individual organizations, caused by institutional and technological factors at an organizational level. Our observations suggest that many emergency management staff are afraid of becoming distracted by irrelevant or too much non-critical information, which is reflected in the organizational atmosphere (e.g., norms, standards, expectations, etc.). This reluctance is likely to apply as well when people provide information to members of other organizations. To an extent, this is caused by the fact that the relief workers of one agency usually are unaware of the kind of information other

Table 2 Overview of applications used during the exercises

\begin{tabular}{|c|c|c|c|c|}
\hline & Multiteam & CITYGIS & $\mathrm{C} 2000$ & GMS \\
\hline Purpose & $\begin{array}{l}\text { Library and document } \\
\text { sharing }\end{array}$ & $\begin{array}{l}\text { Positioning and } \\
\text { navigation }\end{array}$ & Communication & $\begin{array}{l}\text { Documentation and } \\
\text { monitoring }\end{array}$ \\
\hline Information type & All types of information & Geographic information & $\begin{array}{l}\text { All types of } \\
\text { information }\end{array}$ & All types of information \\
\hline System user & $\begin{array}{l}\text { Dedicated persons on } \\
\text { each level }\end{array}$ & Information manager & Everyone & ECC operators \\
\hline Supported format(s) & Text, photo & Dynamic images & Voice & Text \\
\hline $\begin{array}{l}\text { Coordination models } \\
\text { supported }\end{array}$ & Subscription/ role based & Subscription/role based & $\begin{array}{l}\text { Information push } \\
\text { and pull }\end{array}$ & Information push and pull \\
\hline
\end{tabular}


agencies require. The operators of Multiteam, CITIGIS, and GMS, who should fulfill the information requirements of all the participating agencies, belong to a single agency. However, no special training was provided to help them understand the operations and informational requirements of the other agencies. Moreover, the CITIGIS and Multiteam operators do not use the IOISS in normal (SDM) operations and as such they were unable to effectively perform their temporary role as an operator, which earned them some criticism during the exercises. As a result, many of the IOISS operators passively responded to explicit queries rather than actively disseminating information across multiple agencies. Although $\mathrm{C} 2000$, a standard communication device for routine operations, is suitable for inter-agency communication, it is rarely used for that purpose because it was designed for unstructured voice communication, and contacting someone in a different organization can be time-consuming and potentially chaotic when using such a voice network.

\subsubsection{Individual level factors}

A major issue at the individual level is that no emergency responder has enough time and cognitive resources to absorb and process all information that becomes available during an emergency. In the MDM exercises we studied, COPI leaders spent $30 \mathrm{~min}$ or more collecting information and directing the operations of their own agency, followed by a 15-min interaction with other COPI members for inter-agency coordination. This short cycle repeated itself until the emergency situation was resolved. Although information technology is supposed to relieve some of this burden, the researchers have noticed that there is a lack of trust in the quality of information provided by the IOISS. In one of the COPI teams, the COPI leader completely ignored any information about the incident area that the Information manager (IM) prepared using CITYGIS. Instead, he used a paper map to discuss the best possible route to the incident location. When asked why he acted in this way, he responded that he simply did not trust the information provided by the CITYGIS application based on earlier experiences. He felt that existing IOISS have little to offer that may improve the performance of his organization's objectives. While CITYGIS had been recently introduced to most of the participants of the exercise, first responders seem to be extremely risk-aversive when it came to adopting new IOISS, especially when they suspect the quality of information or systems involved. From an institutional point of view, this kind of attitude could be tolerated because the current GRIP plan appoints a lowerranking police officer as the IM of a COPI and sometimes even of a ROT decision-making unit. The situation further deteriorates by the misalignment of the regular duty (police
Table 3 Overview of factors influencing information sharing and coordination

\begin{tabular}{|c|c|}
\hline Level & Factor \\
\hline Community & $\begin{array}{l}\text { - Formal inter-agency communication channels } \\
\text { - Structure \& procedures for MDM operations } \\
\text { - Feedback/incentive mechanism (e.g., measurement, } \\
\text { evaluation, reinforcement, mutual benefits) } \\
\text { - Information filtering \& selective dissemination } \\
\text { - Mutual adjustment through interaction and familiarity } \\
\text { of others roles } \\
\text { - Interface with mediators (i.e., Multiteam/ CITYGIS/ } \\
\text { GMS operators) }\end{array}$ \\
\hline Agency & $\begin{array}{l}\text { - Norms for inter-agency info sharing } \\
\text { - Knowledge about other agencies' operations } \\
\text { - Alignment of primary duty and MDM duty } \\
\text { - IOISS integration with organizational IT/routine use } \\
\text { of ICTs } \\
\text { - Technology training }\end{array}$ \\
\hline Individual & $\begin{array}{l}\text { - Workload for responsible duties } \\
\text { - Motives to use IOISS } \\
\text { - Relational power (rank) } \\
\text { - Technology acceptance propensity } \\
\text { - Trust in IOISS } \\
\text { - Perceived information quality and system quality } \\
\text { - IOISS familiarity \& training }\end{array}$ \\
\hline
\end{tabular}

officer) and the emergency-related duty (Info Manager) of CITIGIS operators.

Table 3 summarizes our observations regarding the factors that may influence inter-organizational information sharing, along with the corresponding levels at which the factors can create problems or solutions. Crisis management involves human actors operating in an organizational structure using the institutionalized rules and technologies, and in this sense, it can be viewed as a socio-technical system. The key contribution of the socio-technical approach is that it allows us to consider the interdependencies among the various technological and social systems as a way of optimizing the performance of the systems (Bostrom and Heinen 1977). This means that a classification of the social and technological factors impeding or facilitating information sharing and coordination is useful. Because the social dimensions exert a subtle, yet profound effect on information sharing, we decided to conduct a survey to gain a better understanding of the dimensions.

As described above, various institutional, technological and environmental elements can affect multi-agency cooperation and influence the sharing and coordination of information at different levels. Based on these observations, we wanted to gain an in-depth understanding of the factors influencing information sharing and coordination 


\section{Questionnaire survey study}

We carried out a questionnaire survey to triangulate and work out some of the findings from the qualitative case study in greater detail. While all the participants of the exercises were motivated and did their best to make the exercise a success, they turned out to be less than impressed by the actual levels of inter-organizational information sharing during the exercises. With regard to the statement "information sharing among participating teams was very successful in the exercise," $57.3 \%$ disagreed $^{4}$, with a mean agreement value of 3 . Perceived success in information sharing is significantly and positively correlated to perceived success of the exercise ( $r=0.415, p<0.001,2$-tailed) measured by the statement "Most participants would say that the exercise was very successful". It is in this context that the factors at the various levels are evaluated.

\subsection{Community level factors}

\subsubsection{Incentive mechanisms and supporting environments}

Information sharing across different DMOs is now strongly backed up by institutional support. About three quarters of participants we surveyed agreed that there is a law/ regulation $(77 \%)$ and/or a higher authority (76\%) that obliges their agency to share proprietary information with other DMOs. Some (19.2\%) even indicated that they may be penalized for refusing to share their information with other agencies. We assume that strong institutional support is common in many countries with a high level of disaster awareness, partly due to recent large-scale disasters such as 9/11, hurricane Katrina, and the Indian Ocean Tsunami. Nevertheless, this may be a key discriminator when the inter-organizational information sharing practices are compared across different nations or legal jurisdictions.

The case study findings indicate that the lack of feedback mechanisms made it impossible to track the usage and evaluate the performance of IOISS. An important problem caused by this state of affairs is the lack of institutional incentive mechanisms for cross-agency information sharing, which means that the only incentive people have for sharing information is an emotional one. While it will be practically impossible to track and reward individual contributions in a disaster situation, emotional reward can still be provided by publicly identifying, crediting and appreciating the shared information after the emergency has

\footnotetext{
${ }^{4}$ [Agreed|Disagreed] percentage represents the proportion of respondents whose answer is [5 or higher | 3 or lower] on a seven-point interval scale agree vs. disagree type question with anchors: 1 . Strongly disagree, 4.Neutral, 7.Strongly agree
}

been resolved. Unfortunately, it was evident in our survey that the participants in the exercises had not received sufficient emotional incentives for sharing proprietary information with other agencies via IOISS. $66.7 \%$ of our survey respondents disagreed that they receive emotional rewards for positive results of information sharing via IOISS. Also, $68 \%$ of them disagreed with the statement that their station ${ }^{5}$ was publicly credited when their proprietary information helped other agencies succeed. Based on these findings, we argue that institutional incentive mechanisms for inter-organizational information sharing are to a large extent missing, while a feedback mechanism may help improve inter-agency information sharing.

Proposition 1 Institutionalized incentive mechanisms for individual agencies will have a positive impact on interagency information sharing.

\subsubsection{Distribution of IOISS benefits}

With regard to the public value of the IOISS, $72 \%$ of the respondents agreed that IOISS is valuable to the disaster management community as a whole. However, about the same percentage $(74.7 \%)$ expressed their dissatisfaction with the value that the existing IOISS offer. Interestingly, satisfaction with the collective value of IOISS is significantly and positively correlated to its fair value for all DMOs ( $r=0.235, p=0.05$, 2-tailed), but not to its gross benefit to the entire community (Table 4). Nevertheless, a strong positive correlation $(r=0.315, p=0.01,2$-tailed $)$ was found between the perceptions of overall value and fair distribution of the value to all organizations in the DM community, indicating that perception of fairness among the system users was important. From these results, we can infer that emergency responders weigh the fairness of IOISS benefits more than their aggregate value at the community level when it comes to their satisfaction with the public value of IOISS.

These results can be applied to elaborate the abovementioned incentive mechanisms. That is to say, community level incentive mechanisms should be transparent and provide every relief agency with a fair share of the benefits from the inter-organizational information sharing systems. How well an incentive mechanism is designed to insure a fair value of inter-agency information sharing (e.g., provide a non-information compensation for information givers) will determine the extent to which the agencies will be satisfied with IOISS, and thus actively share their informa-


zip code area.
} 
Table 4 Correlations: satisfaction with IOISS

\begin{tabular}{llll}
\hline & Mean & Satisfaction & Aggregate \\
\hline Satisfied with what IOISS offer to the DM community as a whole. & 2.64 & 1 & \\
IOISS are valuable to the DM community as a whole. & 5.48 & 0.041 & 1 \\
IOISS offer fair value to all participating DM organizations. & 3.62 & $0.235^{*}$ & $0.315^{* *}$ \\
\hline
\end{tabular}

$* p<.05 ; * * p<.01$

tion with others. We add the following proposition to reflect this point:

Proposition 2 Fair distribution of the benefits from interagency information sharing systems will have a positive impact on inter-agency information sharing.

Nevertheless, it should be noted that fairness and satisfaction may not be correlated to the effectiveness of IOISS in meeting overall objectives in MDM.

\subsection{Agency level factors}

When an IOISS was defined as a networked and computerized system that enables information sharing across organizational boundaries ${ }^{6}$, there was a virtual consensus regarding its importance. A vast majority of the respondents agreed that the use of IOISS is crucial in realizing the primary objectives of their station $(90.4 \%)$ that their station was likely to perform better by using IOISS (100\%) and that a successful operation of their station depended on its utilization (90.7\%). A similar consensus was also found when it came to inter-organizational information dependency. Most of the respondents agreed that having access to proprietary information of other relief agencies was important in achieving their own objectives (88\%), performance (96\%), and successful operation (89.3\%). However, no such consensus emerged with regard to operational dependency. That is to say, a fair number of respondents believed that sharing their agency's proprietary information with other agencies was not necessary ${ }^{7}$ to realize their own station's objectives (24\%), performance (36\%) and success $(20 \%)$. This discrepancy suggests that relief workers do not expect to benefit from sharing their own information with others or do not understand the roles played by other agencies within multi-agency operations, while they focus on gaining access to other agencies' information to fulfill their immediate responsibilities. Correlations among these three importance perceptions ${ }^{8}$ also support our interpreta-

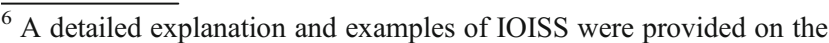
survey questionnaire.

${ }^{7}$ Disagree on the necessity.

${ }^{8}$ Answers to the three questions for each perception were averaged.
}

tion. The perceived importance of information from elsewhere was significantly and positively correlated to perceived importance of IOISS ( $r=0.394, p<0.01$, 2-tailed), but that of sharing own information with other agencies was not $(r=0.196, p>=0.5)$ (see Fig. 3). We can infer from these asymmetric correlations that the IOISS is mainly seen as a tool that enables emergency responders to access the information of other agencies (pull), but not as a means of sharing their own information with others (push).

An ANOVA test (see Table 5) was conducted to explain the potential effects of organizational types (i.e., fire brigades, EMS, law enforcement agencies, ACT/Intelligence/Defense agencies), a community level factor, on the variance in perceived operational dependency. However, the group mean difference was non-significant $(p=0.450)$, suggesting that the weak perception of operational dependency was caused by agency-level rather than community-level factors. Nevertheless, this finding should be validated with more data, because the number of cases in each sub-group (i.e, organizational type) was less than 20 for the ANOVA test.

These results mirror the case study findings with regard to the reluctance to distract other relief workers by providing them with irrelevant information. Determining whether a piece of information is crucial or a mere distraction for others is a complicated endeavor. Most first responders have a limited understanding of the MDM operations as a whole and of the information that may be useful or necessary to other agencies. Therefore, understanding operational dependency (i.e., how can my information help other agency, which will in turn help my agency's operations) and the information requirements of participating relief agencies (i.e., who needs what information and how badly?) can have a catalytic impact on interagency information sharing (Ren et al. 2008) and motivate more responders to share their information actively with other agencies. Thus we present the following proposition.

Proposition 3 Understanding the operations of other agencies will have a positive impact on inter-agency information sharing.

The norms, standards and values institutionalized within agencies are to be important determinants of individual behavior, especially when that behavior is easy to observe 


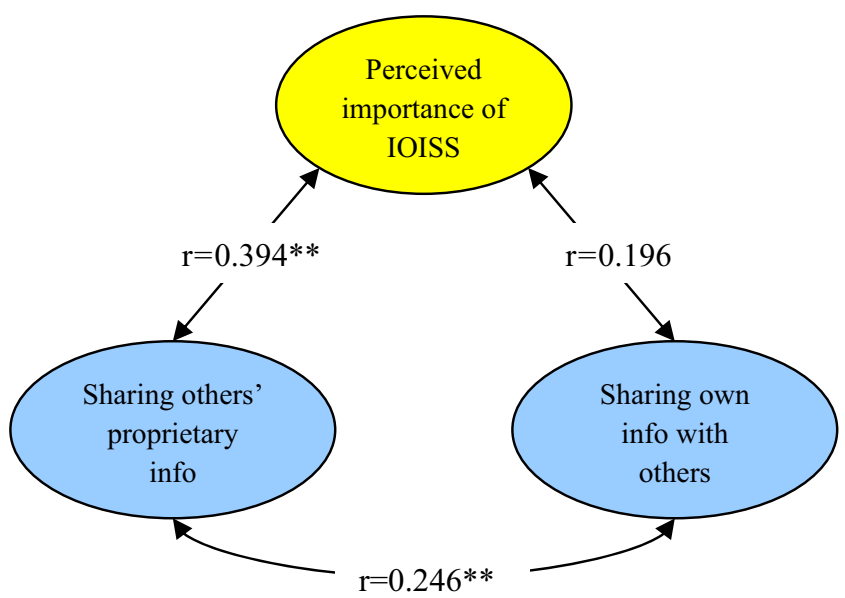

Fig. 3 Correlations

by the individual's reference group (Ajzen 1991; Lee and Rao 2007). Not surprisingly, the respondents expressed mixed perceptions when it came to organizational support (Venkatesh and Davis 2000) for inter-organizational information sharing. Indeed, the distribution of the perceived support from the head of their station, their peers and the general atmosphere ${ }^{9}$ show a somewhat bi-polar pattern, with many respondents choosing one of two extreme values (i.e., 1. Strongly disagree or 7. Strongly agree). We suspect that these mixed results may be due to the fact that the participating agencies often have different responsibilities, and thus different stakes in the situation depending on the organizational type to which they belong. However, an ANOVA test failed to identify any statistically significant difference $(p=0.245)$ in perceived agency support between the four organizational types (i.e., fire brigades, EMS, law enforcement agencies, ACT/Intelligence/Defense agencies) (Table 6). Nevertheless, these results should be validated in a follow-up study with a larger sample size.

As shown in the results presented above, this agency level factor highly varies from one agency to another and, unfortunately, few agencies encourage their members to share information across organizational boundaries. Thus, nurturing organizational norms, standards, and values that encourage the sharing of proprietary information with other agencies will greatly improve inter-agency information sharing.

Proposition 4 Organizational norms, standards, and values for information sharing will have a positive impact on inter-agency information sharing.

\footnotetext{
$\overline{9}$ These three items (i.e., head, peer, general) were averaged to measure agency-level support.
}

\subsection{Individual level factors}

In literature, it is often stated that IOISS for crisis management should be embedded in everyday routines. However, in the case study we have observed a separation of IOISS for MDM and ICTs for daily operations (SDM), which prompted various issues at the organizational and personal levels. As was perhaps to be expected, technological difficulties associated with sharing information using IOISS has turned out to be a major challenge. A vast majority of the respondents indicated that sharing their proprietary information with other agencies via IOISS is difficult $(77 \%)$ and requires an additional effort $(89.3 \%)$, that IOISS is poorly integrated into their internal information systems $(86.3 \%)$, and that the user interface of IOISS is not intuitive and user-unfriendly (70.3\%). Consequently, we propose the following:

Proposition 5 Ease-of-use of an IOISS will have a positive impact on inter-agency information sharing via the IOISS.

In short, the participants indicated that they found the systems difficult to use and that they needed to make an extra effort to share information with others, which resulted in a situation whereby they were reluctant to use the technology at their disposal (Taylor and Todd 1995; Venkatesh et al. 2003). Especially when they felt the time pressure and were trying to deal with the information that came their way, they would focus on dealing with the situation at hand rather than taking the time to familiarize themselves with a new IOISS. Therefore, making sure that potential users are familiar with the IOISS they are expected to use will significantly improve inter-agency information sharing, while system integration at agency level can streamline information flow across organizational boundaries.

Turoff et al. (2004) suggest that such usability of IOISS can be significantly improved when IOISS are integrated in the daily operations of each relief worker and that any IOISS that is not used on a regular basis before an disaster will never be of use in an actual disaster. This brings us to our final proposition:

Proposition 6 Integration of an IOISS in the daily routines will have a positive impact on inter-agency information sharing via the IOISS.

\section{Discussion}

In this paper, we present the findings of our 2-year research on information sharing in a multi-agency disaster management context. We combined a case study approach and a questionnaire to arrive at grounded arguments and a set of 
Table 5 Perceived importance of sharing own info with other organizations

Descriptive stats.

\begin{tabular}{|c|c|c|c|c|c|c|c|c|c|c|}
\hline & \multicolumn{4}{|c|}{ Group (Organizational type) } & & \multirow{2}{*}{$\begin{array}{l}\text { Sum of } \\
\text { Squares }\end{array}$} & \multirow[t]{2}{*}{ df } & \multirow{2}{*}{$\begin{array}{l}\text { Mean } \\
\text { square }\end{array}$} & \multirow[t]{2}{*}{ F-Value } & \multirow[t]{2}{*}{ Sig. } \\
\hline & $\begin{array}{l}\text { Fire } \\
\text { brigade }\end{array}$ & $\begin{array}{l}\text { Emergency } \\
\text { Medical }\end{array}$ & $\begin{array}{l}\text { Police/Law } \\
\text { enforcement }\end{array}$ & $\begin{array}{l}\text { ACT, Intel } \\
\& \text { Defense }\end{array}$ & & & & & & \\
\hline $\mathrm{N}$ & 19 & 16 & 16 & 14 & Between & 5.917 & 3 & 1.972 & .894 & .450 \\
\hline Mean & 5.333 & 4.604 & 4.854 & 4.642 & Within & 134.589 & 61 & 2.206 & & \\
\hline Std.Dev & 1.392 & 1.394 & 1.259 & 1.897 & Total & 140.506 & 64 & & & \\
\hline
\end{tabular}

propositions from our observations and quantitative data analyses. Our observations and statistical analysis suggest that almost all the stakeholders studied agree that information sharing is important, to the success of their own organization and to the exercise as a whole. However, it was evident that they are mainly concerned with obtaining information from others, rather than providing others with information at their disposal. The actual level of information sharing across different organizations is often limited, although it is being promoted. Our case study and survey allowed us to identify some factors that can facilitate or impede efficient and effective inter-organizational information sharing at various levels.

\subsection{Community level issues}

At the national level, authorities and laws can stimulate inter-organizational information sharing by implementing institutional mechanisms (Goes and Park 1997) that dictate organizational policies and guidelines. According to our research findings, most of the institutional conditions with regard to the context of our case study are in place. There is a law that regulates inter-organizational information sharing, and we found evidence that politicians and managers are promoting it actively. On the other hand, it is less clear how emergency responders perceive the value of IOISS to the disaster management community as a whole, while such a perceived public value can influence the use of IOISS
(Hollander 1990). One way to improve that perception is to involve the various organizations in designing the systems and integrating them into everyday operations to make sure they are actually used (e.g., Turoff et al. 2004). Although it was evident that a fair distribution of the benefits of IOISS are an important factor with regard to its perceived value, more research is needed to understand the value perception and design mechanisms to assure all stakeholders get their fair share of the benefits of IOISS.

With regard to the technological aspects of MDM coordination, information sharing processes should deploy better mechanisms to ensure relevant information is not filtered out during the sharing process. The information sharing process should be simplified, as fewer steps mean less possible points of failure. Emerging notions, such as network-centric operations (Alberts et al. 2002), underline the need to equip relief workers with the technological expertise needed to share and coordinate information across organizational boundaries. The steps involved should be made more transparent to see where information is being blocked (which rules work and which do not). Hence, designing information systems not only has technological or informational dimensions, but also involves the coordination and facilitation of cross-agency/ cross-level interactions of multiple parties, which is necessary to make the inter-agency information sharing system function. More insight into these processes and analysis is necessary.

Table 6 Organizational supports for inter-organizational information sharing

\begin{tabular}{|c|c|c|c|c|c|c|c|c|c|c|}
\hline \multicolumn{5}{|c|}{ Descriptive stats. } & \multicolumn{6}{|c|}{ ANOVA Table } \\
\hline & \multicolumn{4}{|c|}{ Group (Organizational type) } & & \multirow{2}{*}{$\begin{array}{l}\text { Sum of } \\
\text { Squares }\end{array}$} & \multirow[t]{2}{*}{ df } & \multirow{2}{*}{$\begin{array}{l}\text { Mean } \\
\text { square }\end{array}$} & \multirow[t]{2}{*}{ F-Value } & \multirow[t]{2}{*}{ Sig. } \\
\hline & $\begin{array}{l}\text { Fire } \\
\text { brigade }\end{array}$ & $\begin{array}{l}\text { Emergency } \\
\text { Medical }\end{array}$ & $\begin{array}{l}\text { Police/Law } \\
\text { enforcement }\end{array}$ & $\begin{array}{l}\text { ACT, Intel } \\
\text { \& Defense }\end{array}$ & & & & & & \\
\hline $\mathrm{N}$ & 19 & 16 & 16 & 14 & Between & 16.058 & 3 & 5.353 & 1.422 & .245 \\
\hline Mean & 5.088 & 3.792 & 4.208 & 4.179 & Within & 229.602 & 61 & 3.764 & & \\
\hline Std.Dev & 1.662 & 1.955 & 1.780 & 2.402 & Total & 245.660 & 64 & & & \\
\hline
\end{tabular}




\subsection{Agency level issues}

At the agency level of disaster management, there are a number of complex issues that play a role. Often, disaster management communities are transient in nature, involving plug and play teaming and information sharing (Faraj and Xiao 2006). Surprisingly enough, agencies within the various stakeholder groups (e.g., different police stations), which at face value may appear to be homogeneous, have different opinions concerning information sharing. Although information sharing may be stimulated at a national level, there are some noticeable skeptics at the station (agency) level. First responders from some stations tend to focus on their immediate tasks and limit their information processing (e.g., search, sharing, and utilization) to a small set of highly relevant data, to make sure they not be distracted from their own activities (Rao et al. 1995). As a consequence, they become less aware of and/or interested in others, as becomes clear from the survey results. This problem can create a vicious cycle of 'reluctance to share information with other agencies' - 'lack of awareness of and/or interest in others' roles in a big picture'-'inability to pinpoint relevant information from/to others, so being more reluctant to share'. Mixed responses in survey data also make it clear that there is no unified view, even within individual stakeholder groups, with regard to most issues involved in sharing information. For example, while some disaster management staff from one organizational type (e.g., a police station) think that understanding each other's operations is a key success factor, others within the same type of organization type (e.g., another police station) think this is not necessary.

With regard to indirect rewards, inter-organizational information sharing for disaster management usually does not involve financial rewards for agencies or individuals contributing information, and emotional rewards and acknowledgement of their credit are often the only incentive to volunteer information (Hollander 1990). However, the survey results show that emergency responders do not receive a satisfactory level of such implicit rewards. This lack of incentives at agency and individual level may result in the current practice whereby emergency responders focus on their own tasks and are oblivious of the value their information may have to others. Helping disaster management personnel understand the big picture of MDM situation is thus an important element in achieving a higher level of inter-agency information sharing and successful MDM operations as a whole. In the context of the MDM, we studied rewards could take the form of demonstrating and acknowledging the value of shared information to the complete exercise. Knowing which problem was solved or which obstacle was removed by the information that certain individuals provided to others, and how the information contributed to the success of the exercise as a whole and that of particular agency will reinforce people's motivation for sharing information.

\subsection{Individual level issues}

Our observation shows that there are a number of steps that need to be taken to share information across organizational boundaries. Information first needs to be collected, after which the person who collected it should decide to give it to others within their own agency (e.g., police, fire brigade), and the call center of one group of stakeholders in the ERC should communicate the information to the reporting center of another stakeholder group (this is known as 'silo-to-silo' communication), even though they are in the same physical location. The second stakeholder in turn should decide whether or not to share the information with all of its own type of stakeholders. According to Orton and Weick (1990), each individual makes sense of the information and passes it on, which gives meaning to information and helps create plausible images that rationalize what is going on. Sense-making requires making assumptions and giving significance, and it sometimes involves neglecting things that may be important. Furthermore, Orton and Weick (1990) found that the severity of a crisis and things like commitment, capacity and expectations affect sensemaking during a crisis. The subjective sense-making and filtering by participants make the information sharing process more difficult. The complexity of this process resulted in some skepticism about the possibility of sharing information. Every step can result in a disposal or delay of information in a situation where time is crucially important. Emergency responders in one organization (e.g., fire brigade) decide what is relevant for another organization (e.g., police) without knowing enough to be able to decide whether or not the other organization really needs the information. Furthermore, the persons in the report center sometimes have no practical experience in their own area. As a consequence, a number of information filters are needed to avoid information overload, which may actually result in filtering out relevant information. It is very hard to determine how well the participants in the exercises we studied handled this process. It is a black box with potentially many points of failure. In fact, survey responses about the perceived level of inter-organizational information sharing were quite inconsistent, even within the same organizational type, suggesting that individual respondents neither have control over nor do they understand the complex process of inter-organizational information sharing. We would argue in favor of giving empowered operators and end-users greater control over information, instead of building in filters at a centralized location. In support of this argument, the survey results revealed that 
information sharing via IOISS involves a high level of complexity and can be a major obstacle to information sharing. This is quite surprising, because most modern information systems have undergone a rigorous process to ensure their user-friendliness. Given the lack of incentive to use IOISS to share information, IOISSs that require extra time and effort without guaranteeing effective communication can seriously impeded information sharing efforts among DMOs (Venkatesh 2000; Venkatesh et al. 2003).

We also noticed that, although many of the participants really wanted to share their information with other organizations, despite their good intentions the information sharing failed. Earlier studies suggest that information sharing should be role-based (personalized) and context and stakeholder-specific (Bui et al. 2000; Chen and Dahanayake 2006) to ensure that all people have a basic understanding of the situation at hand (e.g., Endsley and Garland 2000). Our observation revealed that there is a mismatch between the demand for and supply of information, which is bound to result in more frictions in MDM operations. It is very difficult to predict which information is relevant and which is not. Especially with regard to emergency response situations, matching supply and demand is an extremely challenging yet critical task for IOISS developers. Another challenge facing information system developers is to ensure that new systems will help realize the objectives of individual stakeholders, while at the same time maintaining their usefulness.

\section{Conclusions and recommendations}

In this study, we identified a large number of obstacles and challenges based on a literature research, field observations and a survey. It would seem that there is no single factor that impedes or facilitates information sharing and coordination. Information sharing and coordination is influenced by obstacles and located within and between the community, agency and individual levels. All three levels contain institutional and technological elements. Solving problems at one particular level only is unlikely to improve information sharing and coordination. The performance of multiagency disaster management will improve when and only when the relevant obstacles are dealt with simultaneously at the various levels. In our case study, a number of IOISS systems were introduced to the participating agencies. However, due to institutional factors, the systems were ignored by a number of people. However, institutional factors, can not only exert a constant influence on the various agencies, but also enable and encourage individuals to share information and coordinate the dependencies. A series of grounded propositions were formulated based on our literature review, observations and questionnaire survey.
These propositions provide guidance for the further development of IOISS systems and offer a theoretical foundation for the successful adoption of such systems. The survey shows that, although the individuals are aware of the need for information sharing and coordination, they find themselves faced with a number of obstacles, including a lack of incentives at institutional, organizational and individual levels, a lack of understanding with regard to the overall operational dependencies between the various agencies, organizational norms and values, emotional reward, system usability, integration of systems in the daily routines, and information and system quality. Information sharing and coordination is often limited and individuals are concerned with obtaining information from others rather than providing their information to others. In addition, we discussed a number of directions of further research, including people's inability to identify relevant information under pressure, the empowerment of and control by individuals and the redesign of information sharing processes.

We are aware that our exploratory case study approach shares some limitations with many studies in a developmental stage and requires a more rigorous validation of our findings. The ability to collect and analyze IOISS log files and to compare them with the results of our survey could have significantly improved the validity of our conclusions. As a result, further research is needed to generalize our findings and to explore ways to overcome the obstacles and challenges we have identified. The logical next step will be to further elaborate the concepts identified in this paper (e.g., obstacles) and to develop a reliable and valid way for measuring these concepts. Due to the constraints identified earlier on, collecting and analyzing research information is a daunting task for most academic researchers. Thus, we feel it would make sense for researchers to pool their knowledge and resources and work together to produce compatible modules of work for future integration or comparison.

Open Access This article is distributed under the terms of the Creative Commons Attribution Noncommercial License which permits any noncommercial use, distribution, and reproduction in any medium, provided the original author(s) and source are credited.

\section{References}

ACIR (2005). De Vrijblijvendheid Voorbij. Op naar een effectieve multidisciplinaire informatievoorziening bij grootschalig gezamenlijk optreden in onze gedecentraliseerde eenheidsstaat. Retrieved september 2006. from www.minbzk.nl.

Ajzen, I. (1991). The Theory of Planned Behavior. Organizational Behavior and Human Decision Processes, 50(2), 179-211. doi:10.1016/0749-5978(91)90020-T.

Alberts, D. S., Garstka, J. J., \& Stein, F. P. (2002). Network-centric warfare: Developing and leveraging information superiority (2nd ed. Vol. 2.): CCRP Publication Series. 
Argote, L. (1982). Input uncertainty and organizational coordination in hospital emergency units. Administrative Science Quarterly, 27(3), 420-434. doi:10.2307/2392320.

ASE (2008). Alle Hens on Deck: ASE Veiligheid. Retrieved June 2008. from www.minbzk.nl.

Auf der Heide, E. (1989). Disaster response: Principles of preperation and coordination. Toronto: C.V. Mosby Company.

Berger, P., \& Luckman, T. (1967). The social construction of reality: a treatise in the sociology of knowledge. London: Penguin.

Bigley, G. A., \& Roberts, K. H. (2001). The incident command system: High reliability organizing for complex and volatile task environments. Academy of Management, 44(6), 1281-1300. doi: $10.2307 / 3069401$.

Bostrom, R. P., \& Heinen, J. S. (1977). MIS problems and failures: A socio-technical perspective. Part I: The causes. MIS Quarterly, 1 (3), 17-32. doi:10.2307/248710.

Bots, P. W. G., \& Sol, H. G. (1988). Shaping Organizational Information Systems through Co-ordination Support. In R. M. Lee, A. M. McCosh \& P. Migliarese (Eds.), Organizational Decision Support Systems. Amsterdam: Elsevier Science.

Bui, T., Cho, S., \& Sovereign, M. (2000). A framework for designing a global information network for multinational humanitarian assistance/disaster relief. Information Systems Frontiers, 1(4), 427-442. doi:10.1023/A:1010074210709.

Chen, N., \& Dahanayake, A. (2006). Personalized situation aware information retrieval and access for crisis response. Paper presented at the 3th International Conference on Information Systems for Crisis Response and Management (ISCRAM2006), Newark, NJ, USA.

Chen, R., Sharman, R., Chakravarti, N., Rao, H. R., \& Upadhyaya, S. J. (2008a). Emergency response information system interoperability: development of chemical incident response data model. Journal of the Association for Information Systems, 9(3).

Chen, R., Sharman, R., Rao, R., \& Upadhyaya, S. (2008b). An exploration of coordination in emergency response management. Communications of the ACM, 51(5), 66-73. doi:10.1145/ 1342327.1342340

Comfort, L., \& Kapucu, N. (2006). Inter-organizational coordination in extreme events: The World Trade Center attacks, September 11, 2001. Natural Hazards, 39(2), 309-327. doi:10.1007/s11069006-0030-x.

Comfort, L., Sungu, Y., Johnson, D., \& Dunn, M. (2001). Complex systems in crisis: Anticipation and resilience in dynamic environments. Journal of Contingencies and Crisis Management, 9(3), 144-159. doi:10.1111/1468-5973.00164.

Comfort, L., Dunn, M., Johnson, D., Skertich, R., \& Zagorecki, A. (2004a). Coordination in complex systems: Increasing efficiency in disaster mitigation and response. International Journal of Emergency Management, 2(2), 63-80. doi:10.1504/ IJEM.2004.005314.

Comfort, L., Ko, K., \& Zagorecki, A. (2004b). Coordination in rapidly evolving disaster response systems: the role of information. The American Behavioral Scientist, 48(3), 295-313. doi:10.1177/ 0002764204268987.

Dawes, S., Creswell, A., \& Cahan, B. (2004). Learning from crisis: Lessons in human and information infrastructure from the World Trade center response. Social Science Computer Review, 22(1), 52-66. doi:10.1177/0894439303259887.

De Bruijn, H. (2006). One fight, one team: The 9/11 commision report on intelligence, fragmentation and information. Public Administration, 84(2), 267-287. doi:10.1111/j.1467-9299.2006.00002.x.

Denning, P. J. (2006). Hastily formed networks. Communications of the ACM, 49(4), 15-20. doi:10.1145/1121949.1121966.

Drabek, T., \& McEntire, D. (2002). Emergent phenomena and multiorganizational coordination in disasters. Lessons from the Research Literature, 20, 197-224.
Dynes, R., \& Aguirre, B. (1976). Organizational adaptation to crises: Mechanisms of coordination and structural change. Disasters, 3 (1), 71-74. doi:10.1111/j.1467-7717.1979.tb00200.x.

Endsley, M., \& Garland, D. (2000). Situation awareness analysis and measurement. Mahwah, NJ: Lawrence Erlbaum Associates.

Faraj, S., \& Xiao, Y. (2006). Coordination in fast-response organizations. Management Science, 52(8), 1155-1169. doi:10.1287/ mnsc. 1060.0526 .

Fisher, C. W., \& Kingma, D. R. (2001). Criticality of data quality as examplified in two disasters. Information \& Management, 39, 109-116. doi:10.1016/S0378-7206(01)00083-0.

Fligstein, N., \& Dauber, K. (1989). Structural change in corporate organization. Annual Review of Sociology, 15.

Fountain, J. (2001). Building the virtual state. Information technology and institutional change. Washington DC: Brookings Institution.

Galbraith, J. (1973). Designing Complex Organizations. Reading, MA: Addison-Wesley.

Galbraith, J. R. (1977). Organization Design. Reading, Massachusetts: Addison-Wesley.

Goes, J. B., \& Park, S. H. (1997). Interorganizational links and innovation: The case of hospital services. Academy of Management Journal, 40(3), 673-696. doi:10.2307/257058.

Granot, H. (1997). Emergency inter-organisational relationships. Disaster Prevention and Management, 6(5), 305-310. doi:10.1108/09653569710193736.

Graves, R. (2004). Key technologies for emergency response. Paper presented at the First International Workshop on Information Systems for Crisis Response and Management ISCRAM2004, Brussels.

de Greef, T., \& Arciszewski, H. (2007). A closed-loop adaptive system for command and control foundations of augmented cognition, lecture notes in computer science, pp. 276-285. Berlin/Heidelberg: Springer.

Helbing, D., Ammoser, H., \& Kuhnert, K. (2006). Information flows in hierarchical networks and the capability of organizations to successfully respond to failures, crises, and disasters. Physica A, 363, 141-150. doi:10.1016/j.physa.2006.01.055.

Helsloot, I. (2005). Bordering on reality: Findings on the bonfire crisis management simulation. Journal of Contingencies and Crisis Management, 13(4), 159-169. doi:10.1111/j.1468-5973.2005. 00472.x.

Hollander, H. (1990). A social exchange approach to voluntary cooperation. The American Economic Review, 80(5), 1157-1167.

Horan, T., \& Schooley, B. (2007). Time-critical information services. Communications of the ACM, 50(3), 73-78. doi:10.1145/ 1226736.1226738.

Junglas, I., \& Ives, B. (2007). Recovering IT in a disaster: Lessons learned from Hurricaine Katrina. MIS Quarterly Executive, 6(1), 39-51.

Kapucu, N. (2006). Interagency communication networks during emergencies: Boundary spanners in multiagency coordination. American Review of Public Administration, 36(2), 207-225. doi:10.1177/0275074005280605.

Kean, T. H., \& Hamilton, L. H. (2004). The 9/11 Report. New York: St. Martin's Press

Killian, L. M. (2002). An introduction to methodological problems of field studies in disasters. In R. A. Stallings (Ed.), Methods of disaster research, pp. 21-49. PA, Philadelphia: Xlibris.

Kouzmin, A., Jarman, M., \& Rosenthal, U. (1995). Interorganizational policy processes in disaster management. Journal of Disaster Prevention and Management, 4(2), 20-37. doi:10.1108/09653569510082669.

Lee, H. L., \& Whang, S. (2000). Information sharing in a supply chain. International Journal of Technology Management, 20(3), 373-387. doi:10.1504/IJTM.2000.002867.

Lee, J., \& Rao, H. R. (2007). Understanding socio-technical environments for acceptance of inter-agency anti/counter-terrorism 
information sharing systems. Paper presented at the 40th Hawaii International Conference on System Sciences (HICSS).

Lin, D., \& Su, Y. (1998). The effect of time pressure on expert system based training for emergency management. Behaviour \& Information Technology, 17(4), 195-202. doi:10.1080/014492998119409.

Lindblom, C. E. (1968). The Policy-Making Process. New Jersey: Prentice-Hall, Englewood Cliffs.

Longstaff, P. H. (2005). Security, resilience, and communication in unpredictable environments such as terrorism, natural disasters, and complex technology. Retrieved July 2007, from http://pirp. harvard.edu/pubs_pdf/longsta/longsta-p05-3.pdf.

Malone, T. W., \& Crowston, K. (1990). What is coordination theory and how can it help design cooperative work systems?. New York, NY, USA: ACM.

March, J. G. (1988). Decisions and Organizations. Oxford: Blackwell.

McEntire, D. A. (2002). Coordinating multi organisational responses to disaster. Disaster Prevention and Management, 11(5), 369379. doi:10.1108/09653560210453416.

Mendonca, D., Jefferson, T., \& Harrald, J. (2007). Collaborative adhocracies and mix-and-match technologies in emergency management. Communications of the ACM, 50(3), 45-49. doi: $10.1145 / 1226736.1226764$.

Miller, H., Granato, R., Feuerstein, J., \& Ruffino, L. (2005). Toward interoperable first response. IEEE IT Professional, 7(1), 13-20. doi:10.1109/MITP.2005.1407799.

Orton, J. D., \& Weick, K. E. (1990). Loosely coupled systems: A reconceptualization. Academy of Management Review, 15(2), 203-223. doi:10.2307/258154.

Otjacques, B., Hitzelberger, P., \& Feltz, F. (2007). Interoperability of E-government information systems: Issues of identification and data sharing. Journal of Management Information Systems, 23 (4), 29-51. doi:10.2753/MIS0742-1222230403.

Pan, S., Pan, G., \& Devadoss, P. (2005). E-government capabilities and crisis management: Lessons from combating SARS in Singapore. MIS Quarterly Executive, 4(4), 385-397.

Quarantelli, E. (1982). Social and organisational problems in a major emergency. Emergency Planning Digest, 9(1), 7-10.

Rao, H. R., Chaudhury, A., \& Chakka, M. (1995). Modeling team processes: Issues and a specific example. Information Systems Research, 6(3), 255-285. doi:10.1287/isre.6.3.255.

Ren, Y., Kiesler, S., \& Fussell, S. R. (2008). Multiple group coordination in complex and dynamic task environments: Interruptions, coping mechansism, and technology recommendations. Journal of Management Information Systems, 25(1), 105130. doi:10.2753/MIS0742-1222250105.

Simon, H. A. (1982). Models of bounded rationality (vol. 2). Cambridge, Mass: MIT.

Stafdirectie Risico- en Crisisbeheersing. (2006). Gecoördineerde regionale incidentenbestrijdingsprocedure Rotterdam-Rijnmond. Retrieved January 2007. from http://www.rhrr.nl/eCache/DEF/1/956.pdf.

Stinchcombe, A. L. (1997). On the virtues of the old institutionalism. Annual Review of Sociology, 23.

Taylor, S., \& Todd, P. (1995). Assessing IT usage: The role of prior experience. MIS Quarterly, 19(4), 561-570. doi:10.2307/249633.

Turoff, M., Chumer, M., Van De Walle, B., \& Yao, X. (2004). The design of a dynamic emergency response management information system (DERMIS). Journal of Information Technology Theory and Application, 5(4), 1-35. JITTA.

Van de Ven, A. H., \& Drazin, R. (1985). The concept of fit in Contingency Theory. Research in Organizational Behavior, 7, 333-365.

Venkatesh, V. (2000). Determinants of perceived ease of use: Integrating control, intrinsic motivation, and emotion into the technology acceptance model. Information Systems Research, 11 (4), 342-365. doi:10.1287/isre.11.4.342.11872.

Venkatesh, V., \& Davis, F. D. (2000). A theoretical extension of the technology acceptance model: Four longitudinal field studies.
Management Science, 46(2), 186-204. doi:10.1287/mnsc. 46.2.186.11926.

Venkatesh, V., Morris, M. G., Davis, G. B., \& Davis, F. D. (2003). User acceptance of information technology: Toward a unified view. MIS Quarterly, 27(3), 425-478.

Weick, K. E. (1988). Enacted sensemaking in crisis situations. Journal of Management Studies, 25, 305-317. doi:10.1111/j.14676486.1988.tb00039.x.

Weick, K. E. (1993). The collapse of sensemaking in organizations: The Mann Gulch disaster. Administrative Science Quarterly, 38 (4), 628-652. doi:10.2307/2393339.

Weick, K. E., \& Sutcliffe, K. M. (2001). Managing the Unexpected: Assuring High Performance in an Age of Complexity. San Francisco: Jossey-Bas.

Nitesh Bharosa is a PhD candidate at the Information and Communication Technology department of the Technology, Policy and Management Faculty within the Delft University of Technology. He holds an MSc degree (2006) in Systems Engineering, Policy Analysis and Management. His research focuses on adaptive information orchestration and information quality assurance in heterogeneous and dynamic multi-agency environments, such as disaster management networks. He has published papers in multiple academic journals and conferences including ISF, ISCRAM, DGo and HICSS, and has served as a special issue/track editor for journals and conferences including ISF and ISCRAM.

JinKyu Lee is Assistant Professor of Management Science and Information Systems in Spears School of Business, Oklahoma State University. He holds a Ph.D. (2007) in MIS from the School of Management, University at Buffalo, Master of Information Systems (1999) from Griffith University, Australia, and B.B.A. (1996) from Yonsei University, Korea. His current research interests include New information \& communication technology applications for public/commercial services, Information security and privacy, and Inter-organizational information sharing. Prof. Lee has published research articles in various academic journals and conferences including Decision Support Systems (DSS), Communications of the ACM (CACM), IEEE Transactions on Systems, Man and Cybernetics (SMC), International Conference on Information Systems (ICIS) and Hawaii International Conference on System Sciences (HICSS), and served as a guest editor/associate editor for special issues of leading journals and conferences such as MIS Quarterly (MISQ) and ICIS. He has also been involved in several National Science Foundation (NSF), National Security Agency (NSA), and Department of Defense (DoD) funded research/educational projects in information security/assurance and e-government areas.

Dr. Marijn Janssen is director of the interdisciplinary Systems Engineering, Policy Analyses and Management (SEPAM) Master programme, manager of the "IT and Business architecture" executive programme and an associate professor within the Information and Communication Technology section of the Technology, Policy and Management Faculty of Delft University of Technology. He has been a consultant for the Ministry of Justice and received a Ph.D. in information systems (2001). His research interests are in the field of e-government, crises management, information coordination, intermediaries, brokers, orchestration and shared services. He is particularly interested in situations in which heterogeneous public and private organizations want to collaborate, in which information technology plays an enabling role and solutions are constrained by organizational realities and political wishes and there are various ways to proceed, all directions having its own implications. He is (associate) editor of various journals, edited several special issues, chaired various conferences and has published over 120 refereed publications. More information: www.tbm.tudelft.nl/marijnj 